\title{
The causes of educational differences in fertility in Sub-Saharan Africa
}

\author{
John Bongaarts*
}

\begin{abstract}
This study first presents an analytic framework that describes the chain of causation linking fertility to its multiple layers of determinants. Next, this framework is applied to analyse the causes of educational fertility differences in 30 sub-Saharan African countries using data from DHS surveys. The results demonstrate that education levels are positively associated with demand for and use of contraception and negatively associated with fertility and desired family size. In addition, there are differences by level of education in the relationships between indicators. As education rises, fertility is lower at a given level of contraceptive use, contraceptive use is higher at a given level of demand, and demand is higher at a given level of desired family size. The most plausible explanations for these shifting relationships are that better-educated women marry later and less often, use contraception more effectively, have more knowledge about and access to contraception, have greater autonomy in reproductive decision-making, and are more motivated to implement demand because of the higher opportunity costs of unintended childbearing.
\end{abstract}

\section{Introduction}

Until the 1970s fertility in sub-Saharan Africa remained high with an average total fertility rate around 6.7 births per woman, and differences between regions and countries were modest. Over the past quarter century, however, significant fertility declines have occurred particularly in eastern and southern Africa, while fertility remains near high pre-transitional levels in many countries in western and middle Africa. As a result, differences between countries have grown large over time. The total fertility rates of individual countries in 2000-05 ranged from a high of 7 births per woman in Niger to below 3 in South Africa (United Nations 2007).

* John Bongaarts, Population council, One Dag Hammarskjold Plaza, New York, NY 10017, USA. Email: jbongaarts@popcouncil.org 
In addition, substantial differences in reproductive behaviour exist between socioeconomic groups within countries. Fertility is usually higher in rural than in urban areas, higher among the uneducated than among better-educated women, and higher in households with low rather than high incomes (Merrick 2001; Singh and Casterline 1985; Rutstein 2002; United Nations 1987). Educational differentials are among the best established and most widely studied (Cochrane 1979; Caldwell 1982; United Nations 1987, 1995; Cleland and Rodríguez 1988; Jejeebhoy 1995; Jeffery and Basu 1996; National Research Council 1999). According to Jejeebhoy (1995) women's education influences reproductive behaviour through five types of autonomy: knowledge, decision-making, physical (ability to move freely outside the home), emotional, and economic and social. The effects of years of schooling remain significant after controlling for many other socioeconomic and behavioural factors (United Nations 1987; Cleland and Rodríguez 1988; Rodríguez and Aravena 1991; Castro Martín and Juárez 1995; United Nations 1995).

After noting sources of data, this study presents an analytic framework that describes the chain of causation linking fertility to its multiple layers of determinants, including use of and demand for contraception, desired family size and level of socioeconomic development (including education). Next, this framework is used to examine and explain the causes of fertility differences by level of female education. The hypothesis is that higher levels of female education are associated with lower levels of fertility, less unmet need for contraception and lower desired family sizes as well as with higher levels of demand for and use of contraception. These results should shed light on the impact on reproductive behaviour that can be expected from raising education levels among women.

\section{Data}

The primary sources of data for this study are the latest available Demographic and Health Surveys conducted over the past decade in 30 countries: ${ }^{1}$ Benin, Burkina Faso, Cameroon, Chad, Congo (Brazzaville), Congo Democratic Republic, Côte d'Ivoire, Ethiopia, Gabon, Ghana, Guinea, Kenya, Lesotho, Liberia, Madagascar, Malawi, Mali, Mozambique, Namibia, Niger, Nigeria, Rwanda, Senegal, South Africa, Swaziland, Tanzania, Togo, Uganda, Zambia, and Zimbabwe.

To document and analyse relationships between different dimensions of reproductive behaviour, five indicators are examined below:

- Fertility as measured by the total fertility rate in the three years before the survey (TFR);

1 Mauritania 2000 and Eritrea 2002 are excluded from this analysis because the DHS data tapes were not available. 
- Contraceptive use as measured by the prevalence rate of all methods among currently married women (U);

- Demand for contraception (spacing or limiting) among currently married women (D);

- The per cent of this demand that is satisfied, estimated as U/D;

- Reproductive preferences as measured by desired family size.

Estimates of these indicators (aggregate and by level of education) are taken from DHS country reports (www.measuredhs.com) or calculated from the data tapes. Following standard DHS practice three education categories are used: no schooling, primary, and secondary and higher, based on country-specific definitions of primary and secondary schooling.

\section{Analytic framework}

The empirical analysis of the causes of fertility differences is guided by the analytic framework depicted in Figure 1. This framework summarises the main factors that determine fertility and the chain of causation that links layers of determinants. Socioeconomic development (e.g. rising level of education) is considered the main cause of a decline in the benefits of children and a rise in their costs that occur over the course of a fertility transition. These changes in the cost/benefit ratio lead parents to want fewer children, and at the same time mortality decline raises child survival so that families need fewer births to achieve the desired number of surviving children.

Figure 1:

Analytic framework for the determinants of fertility

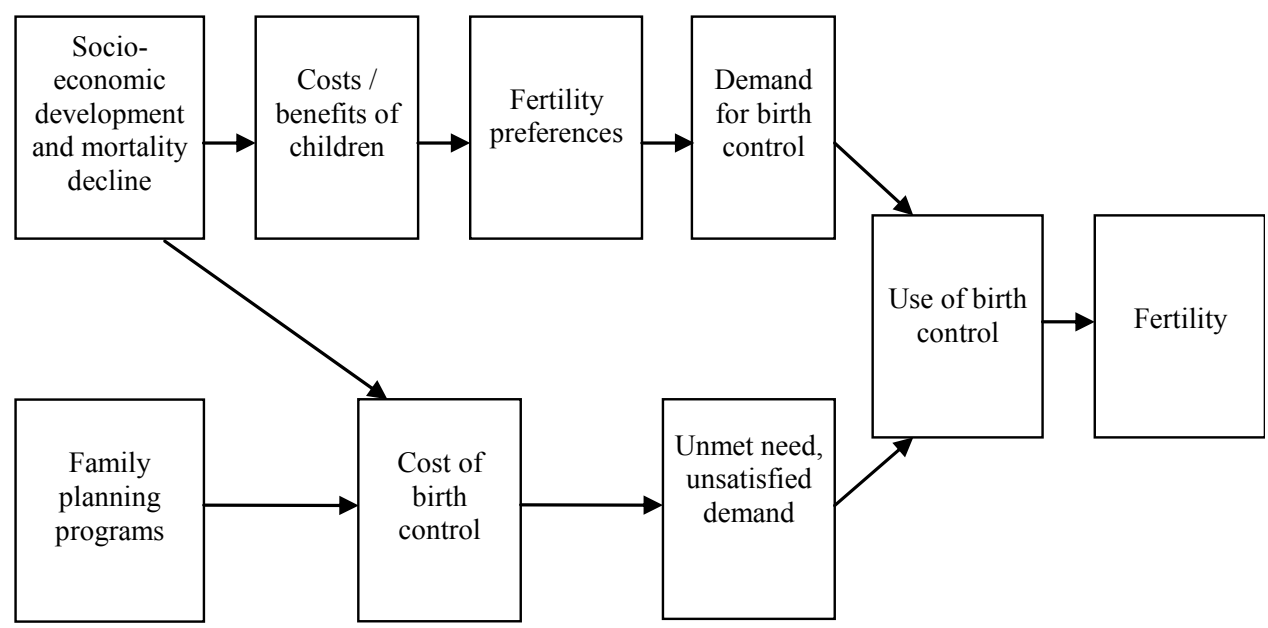

Source: DHS 
These trends in turn raise the demand for birth control (i.e. contraception and induced abortion), and, to the extent that this demand is satisfied, lower fertility results. Family planning programs facilitate this transition by reducing the cost of birth control (broadly defined to include social costs), thus raising implementation of the demand for contraception and reducing the unmet need for contraception. Family planning programs can also change parental perceptions of the costs and benefits of childbearing (e.g. through communication campaigns that emphasise the benefits of smaller families), thereby contributing to declines in fertility preferences.

A full analysis of this framework will not be attempted here, in part because DHS surveys do not collect information on the costs and benefits of children and the cost of birth control. Instead the focus will be on selected variables, starting with fertility and contraceptive prevalence, followed by the demand for contraception and family size preferences, as well as the links between them.

\section{Results}

\subsection{Aggregate results}

Table 1 presents estimates of the four key indicators for each of the 30 countries included in this study. Differences among countries are large, with the following low-high ranges:

- Total fertility rate (births per woman): from 2.9 in South Africa to 7.0 in Niger

- Contraceptive prevalence (per cent): from 2.8 in Chad to 60.2 in Zimbabwe;

- Demand for contraception (per cent): from 23.5 in Chad to 74.7 in Swaziland;

- Desired family size (births per woman): from 2.3 in Swaziland to 8.6 in Chad.

According to the analytic framework these variables are causally related through successive links between layers of determinants. Each of the links relating desired fertility to actual fertility in Figure 1 will now be examined.

\subsection{Effect of contraceptive use on fertility}

Previous studies have found a strong inverse correlation between the TFR and contraceptive prevalence (Ross et al. 2005; United Nations 2001). In pretransitional societies fertility is high and deliberate use of contraception is rare, while in countries at the end of their transition fertility is low and the large majority of couples practice some form of contraception. This correlation between contraceptive prevalence and fertility is confirmed in Figure 2 which plots the relationship between TFR and contraceptive prevalence (among women in union) for the 30 countries included in this study. 
Table 1:

Estimates of total fertility rate, current use of and demand for contraception among married women and desired family size (ages 20-29) for 30 countries in sub-Saharan Africa

\begin{tabular}{|c|c|c|c|c|}
\hline & $\begin{array}{c}\text { Total fertility } \\
\text { rate (births } \\
\text { per woman) }\end{array}$ & $\begin{array}{l}\text { Contraceptive } \\
\text { prevalence (\%) }\end{array}$ & $\begin{array}{c}\text { Demand for } \\
\text { contraception } \\
(\%) \\
\end{array}$ & $\begin{array}{l}\text { Desired family } \\
\text { size } \\
\text { (births/woman) }\end{array}$ \\
\hline Benin $2006(1)$ & 5.7 & 17.0 & 47.0 & 4.7 \\
\hline Burkina Faso 2003 & 5.9 & 13.8 & 42.6 & 5.3 \\
\hline Cameroon 2004 & 5.0 & 26.0 & 46.2 & 5.4 \\
\hline Chad 2004 & 6.3 & 2.8 & 23.5 & 8.6 \\
\hline Congo (Braz.) 2005 & 4.8 & 44.3 & 60.5 & 4.9 \\
\hline Congo Dem. Rep. 2007 & 6.3 & 20.6 & 45.0 & 6.2 \\
\hline Côte d'Ivoire 1998/99 & 5.2 & 15.0 & 42.7 & 4.8 \\
\hline Ethiopia 2005 & 5.4 & 14.7 & 48.7 & 4.4 \\
\hline Gabon 2000 & 4.2 & 32.7 & 60.7 & 4.6 \\
\hline Ghana 2003 & 4.4 & 25.2 & 59.2 & 4.1 \\
\hline Guinea 2005 & 5.7 & 9.1 & 30.4 & 5.3 \\
\hline Kenya 2003 & 4.9 & 39.3 & 65.9 & 3.6 \\
\hline Lesotho 2004 & 3.5 & 37.3 & 68.3 & 2.8 \\
\hline Liberia 2007 & 5.2 & 11.5 & 47.2 & 4.6 \\
\hline Madagascar 2003/04 & 5.2 & 27.1 & 50.8 & 4.5 \\
\hline Malawi 2004 & 6.0 & 32.5 & 61.8 & 3.8 \\
\hline Mali 2006 & 6.6 & 8.2 & 39.5 & 6.1 \\
\hline Mozambique 2003 & 5.5 & 25.5 & 43.9 & 4.9 \\
\hline Namibia 2000 & 4.2 & 43.7 & 65.9 & 3.0 \\
\hline Niger 2006 & 7.0 & 11.2 & 27.1 & 8.5 \\
\hline Nigeria 2003 & 5.7 & 12.6 & 29.5 & 6.4 \\
\hline Rwanda 2005 & 6.1 & 17.4 & 55.3 & 4.1 \\
\hline Senegal 2005 & 5.3 & 11.8 & 43.5 & 5.3 \\
\hline South Africa 1998 & 2.9 & 56.3 & 71.6 & 2.6 \\
\hline Swaziland 2006 & 3.9 & 50.6 & 74.7 & 2.3 \\
\hline Tanzania 2004 & 5.7 & 26.4 & 49.5 & 4.7 \\
\hline Togo 1998 & 5.2 & 23.5 & 55.8 & 4.3 \\
\hline Uganda 2006 & 6.7 & 23.7 & 64.3 & 4.6 \\
\hline Zambia 2001/02 (4) & 5.9 & 34.2 & 61.7 & 4.4 \\
\hline Zimbabwe 2005/06 & 3.8 & 60.2 & 73.7 & 3.4 \\
\hline
\end{tabular}

Source: DHS

This relationship is statistically significant $\left(\mathrm{R}^{2}=0.57\right)$ but individual countries deviate from the best-fitting regression line. This result may be attributable to measurement error, but another plausible partial explanation is related to the role of other proximate determinants. Fertility is directly determined by a set of 
behavioural and biological variables called the proximate determinants (Bongaarts and Potter 1983). Contraceptive use is one the most important of these, but there are a number of others, including proportions married or in union, contraceptive effectiveness, incidence of induced abortion, duration of postpartum infecundability and frequency of intercourse. Over the course of the fertility transition changes occur in these other proximate determinants, with some having negative effects on fertility (e.g. increasing age at marriage) and others having positive effects (e.g. declines in the duration of postpartum infecundability). These effects usually offset one another at least partially, and their net impact is often relatively small compared with the effect of rising contraceptive prevalence (Bongaarts and Potter 1983). However, the net effect of these other factors is not zero, hence deviations from the regression line in Figure 2 are not surprising. A full analysis of the effects of these other proximate determinants will not be attempted here.

Figure 2:

Relationship between total fertility rate and contraceptive prevalence

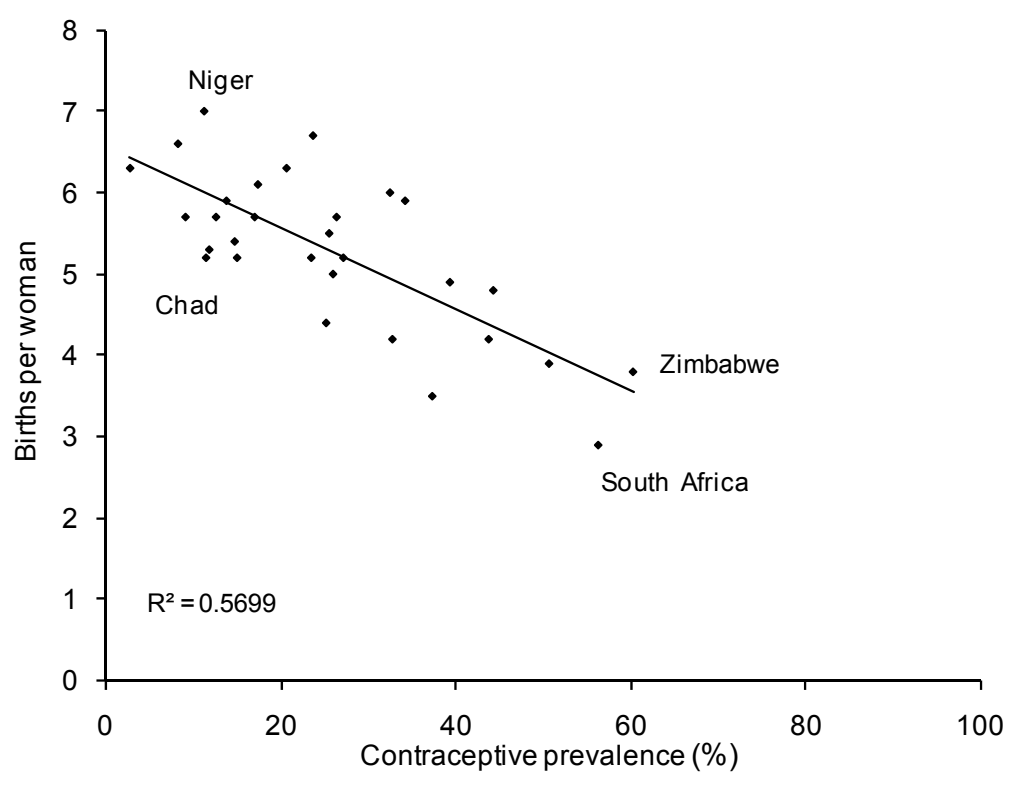

Source: DHS

\subsection{Effect of demand for contraception on use of contraception}

The level of demand for contraception is one of the main direct determinants of contraceptive use. In DHS reports the demand for contraception is measured as 
the level of contraceptive use that would prevail if every fecund woman who wants to avoid pregnancies were currently using contraception. Figure 3 plots use and demand for the 30 countries. $^{2}$ The correlation is again strong with $\mathrm{R}^{2}=0.82$. Demand for (or potential use of) contraception is higher than the level of prevalence (or actual use) in all 30 countries. This difference implies a significant unmet demand/need for contraception (Bankole and Westoff 1995; Casterline and Sinding 2000; Westoff 2001). This issue will be discussed in more detail below.

\section{Figure 3:}

\section{Relationship between contraceptive prevalence and demand for contraception}

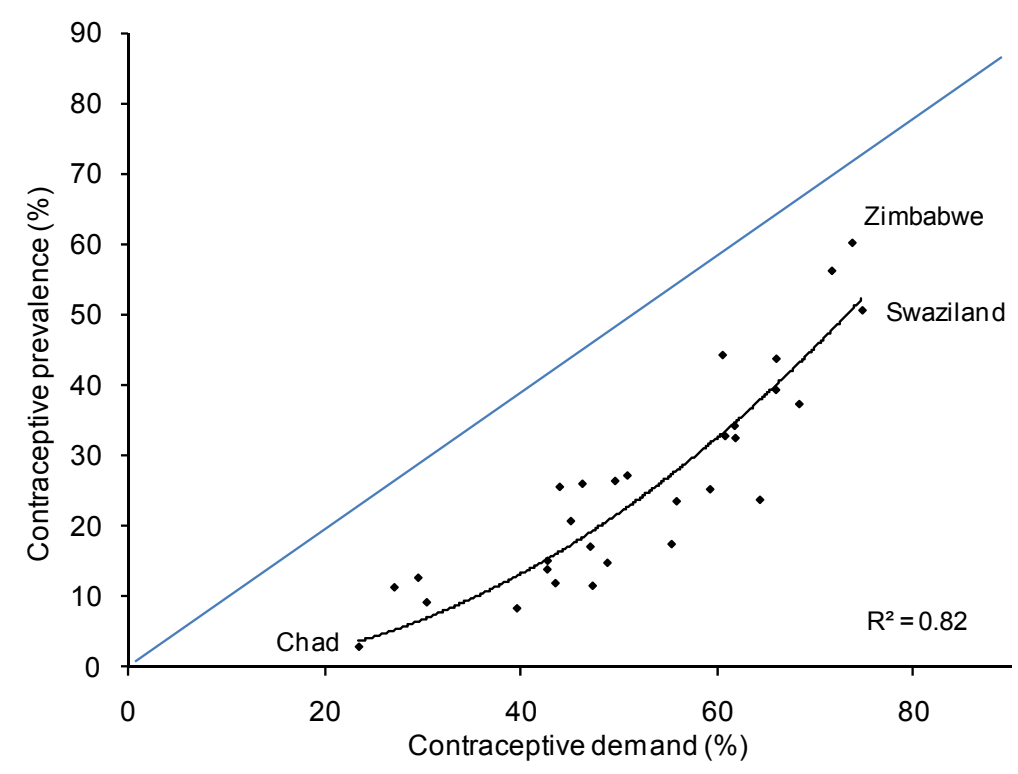

Source: DHS

\subsection{Effect of desired family size on the demand for contraception}

Reproductive preferences are the next link in the chain of causal factors that determine fertility. The DHS collects data for a number of preference measures including ideal family size, desired total fertility rate, desired/mistimed status of the most recent birth and the proportion of women who want to space or limit childbearing. The present analysis relies mainly on the desired family size because it is the most widely used preference measure. The key concern with this indicator is that older women may inflate their stated desired family size to be in accord with the number of children they already have, which may include

Fitted line represents a second-order polynomial with intercept set to zero. 
unwanted births ('rationalisation'). To minimise this potential error, the desired family size among women aged 20 to 29 will be used here as the indicator of fertility preferences.

Figure 4 plots the relationship between demand for contraception and average desired family size. There is a strong inverse correlation between these variables $\left(\mathrm{R}^{2}=0.79\right)$ : the lower the desired family size, the larger the demand for contraception, which is as expected because contraception is the main means by which women implement their preferences for smaller families.

\section{Figure 4:}

Relationship between contraceptive demand and desired family size

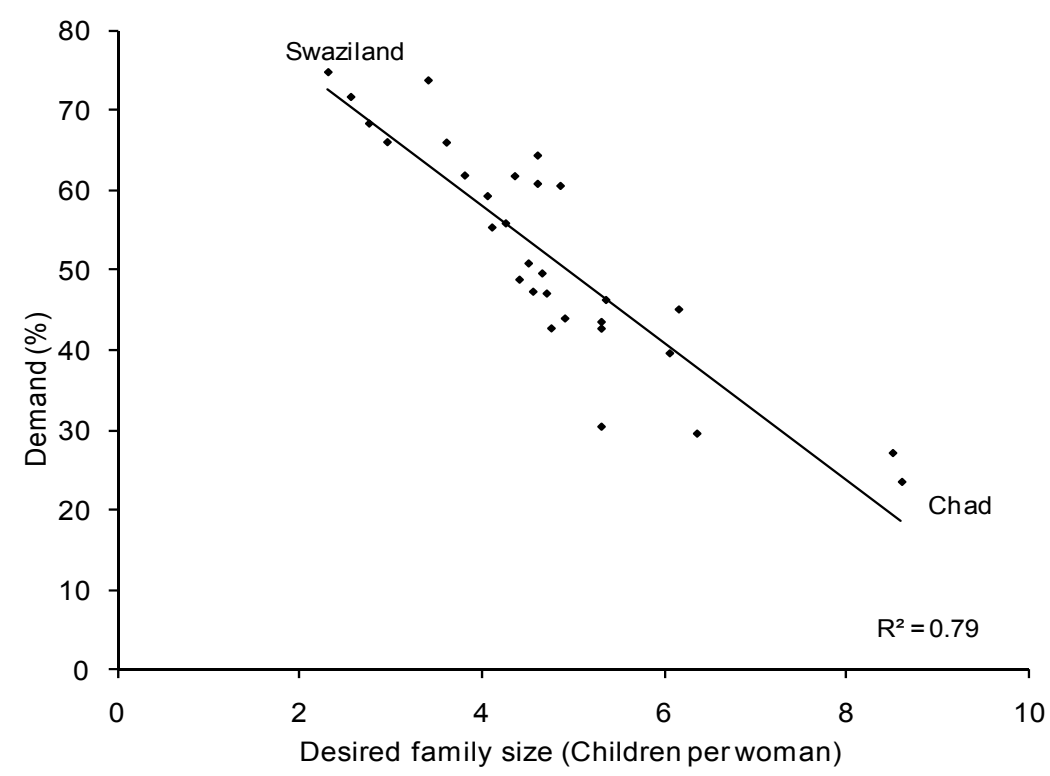

Source: DHS

\subsection{Unmet need for contraception and unwanted fertility}

The preceding results are all in accordance with expectations from the analytic framework: the lower the desired family size, the higher the demand for and use of contraception and hence the lower the fertility. However, the analytic framework does not predict levels of unmet need for contraception and how they might differ among countries.

As seen in Figure 3, levels of demand always exceed observed contraceptive use. Couples whose demand is not satisfied have an 'unmet need' for contraception. The key cause of this unmet need is that contraception is often quite costly to individuals in terms of the commodities, transportation and reimbursement of providers of contraceptives and health care services, even when 
subsidies are provided by the government. In addition, there are significant noneconomic costs such as the fear of side effects, social disapproval and spousal resistance, as well as unnecessary medical barriers (Casterline and Sinding 2002).

Figure 5 plots country-specific levels of unmet need for contraception as a function of the demand for contraception. This relationship has an inverted U-shape: unmet need is highest in countries with intermediate demand and lowest in countries with low and high demand. This pattern is the result of offsetting trends as countries move through the transition (Bongaarts 1997). In pretransitional countries unmet need (and demand) is low because desired family sizes are high, and couples need most of their reproductive years to achieve a large family. Next, in the early stages of the transition, unmet need rises as the desired family size declines, but the use of contraception lags behind the rise in demand. After peaking in mid-transition, unmet need declines in the last phases of the transition as the use (and effectiveness) of contraception catches up with the demand and the cost of unwanted childbearing rises.

\section{Figure 5:}

\section{Relationship between unmet need and demand for contraception}

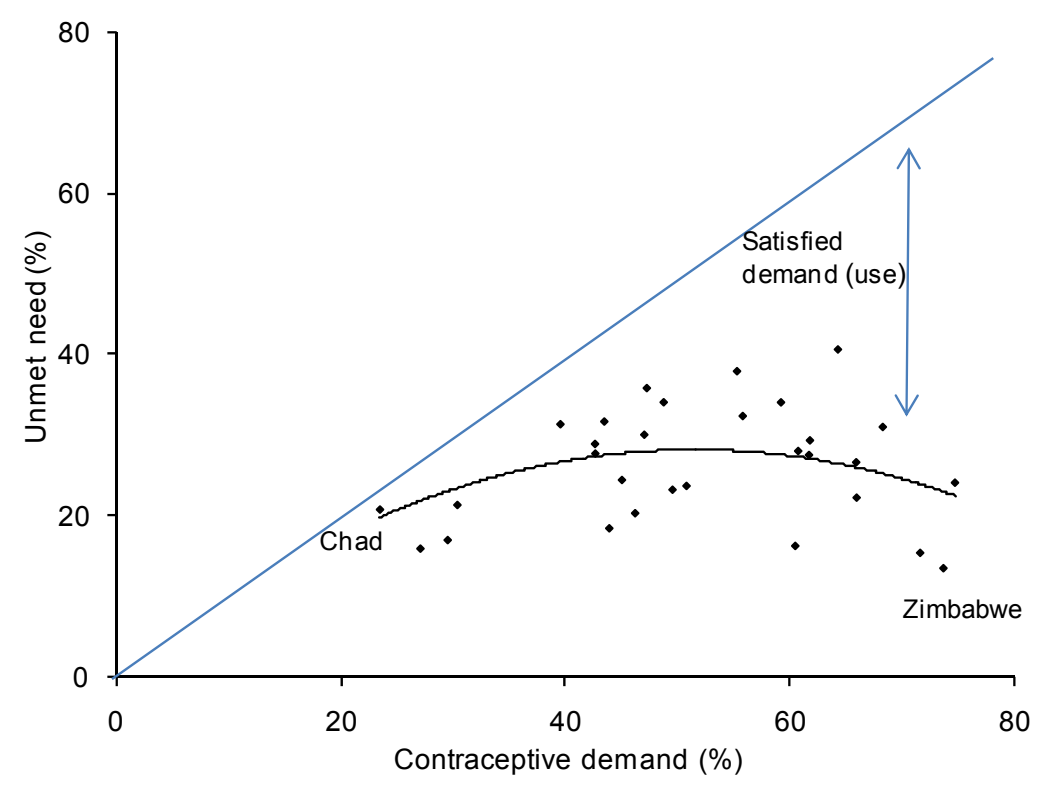

Source: DHS

These trends suggest that the proportion of demand that is satisfied rises as countries move through the fertility transition. This conclusion is confirmed in Figure 6, which shows that as demand rises, the proportion using contraception among women with a demand also rises. For example in Chad contraceptive demand is just 23 per cent and the proportion of this demand that is satisfied is 
only 12 per cent As a result contraceptive prevalence is 2.8 per cent (12 per cent of 23 per cent), which is the lowest level observed in this set of countries. At the other end of the spectrum is Zimbabwe, where demand is 74 per cent and satisfaction is 82 per cent, thus yielding contraceptive prevalence of 60 per cent. The level of satisfaction is a useful indicator of the extent to which women have ready access to quality family planning services and their ability to overcome various economic and social obstacles to using contraception.

\section{Figure 6:}

Relationship between percent of demand that is satisfied and contraceptive demand

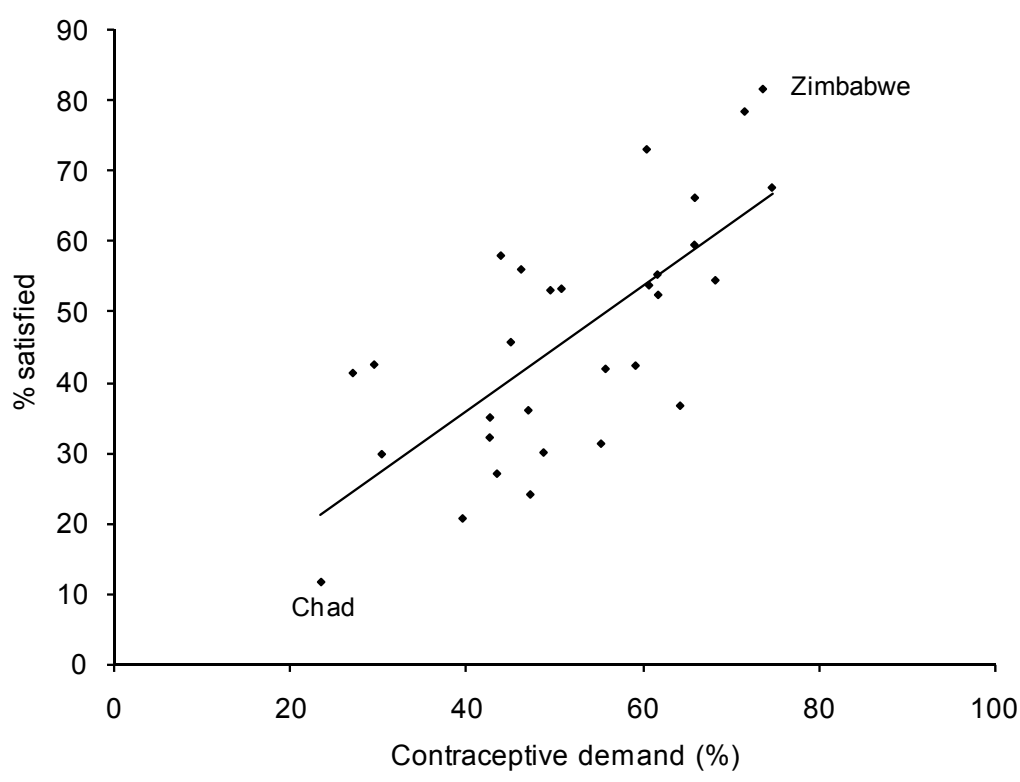

Source: DHS

An unmet need for contraception results in unwanted fertility, which, as shown in Figure 7, also exhibits a weak inverted U-shaped pattern. The explanation is broadly the same as for unmet need. Early in the fertility transition demand for contraception is low, which keeps both unmet need and unwanted fertility relatively low. For example, unwanted fertility is just 0.2 births per woman in Niger and Chad. In mid-transition unwanted fertility is generally highest (e.g. 1.9 births per woman in Swaziland). And at the end of the fertility transition unwanted fertility is relative low again (e.g. 0.6 births per woman in South Africa). In countries in Asia and Latin America that have reached replacement-level fertility, unwanted fertility is typically still lower, and it is reasonable to assume that unwanted fertility will decline further as countries in sub-Saharan Africa reach the end of their fertility transitions in future decades. 
Figure 7:

Relationship between unwanted fertility and total fertility rate

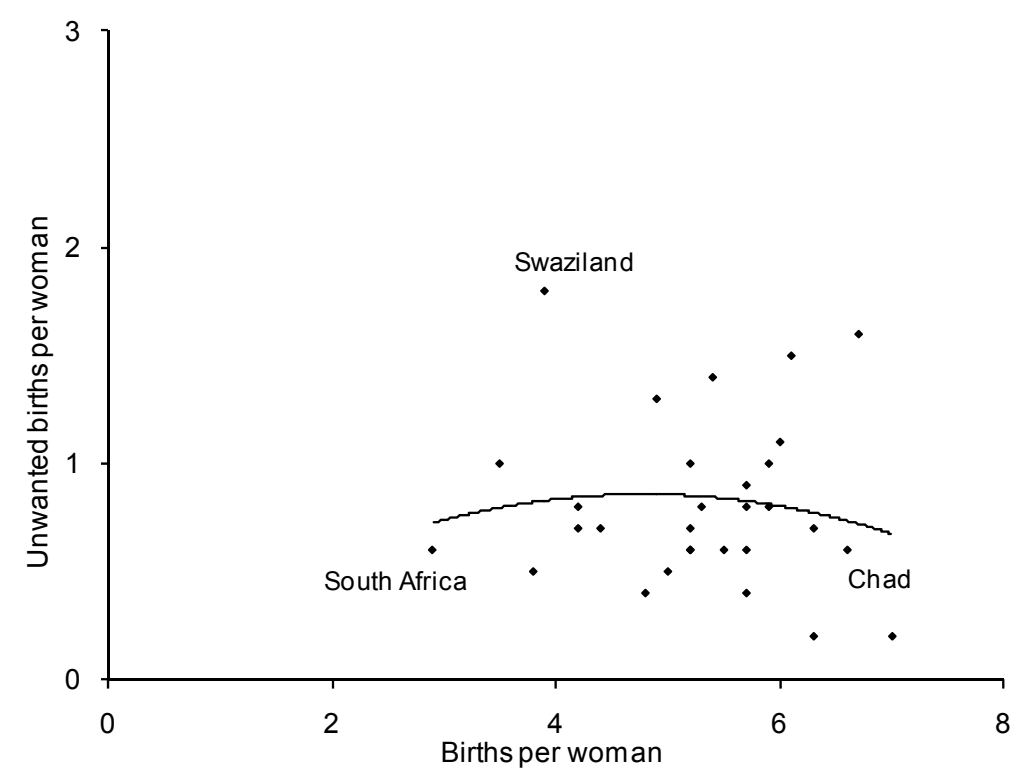

Source: DHS

\section{Educational Differences in Reproductive Indicators}

The preceding section examined differences in country-level indicators. The analysis will now be expanded to investigate educational differences within countries using the same indicators.

\subsection{Regional averages}

As a first step, averages across all 30 sub-Saharan countries (unweighted) are calculated for each of the reproductive indicators by level of education. Figure 8 plots the average TFR and desired family size. Women with secondary or higher education have, on average, lower fertility than women with no education (3.4 vs. 6.3 births per woman), and the same is true for desired family size (3.7 vs. 5.6 births per woman). Figure 9 plots the averages of contraceptive use and demand for contraception by level of education. ${ }^{3}$ Both indicators are positively associated with level of education. The gap between demand and use (unmet need) is lowest among the most highly educated women.

3 Country estimates by education are age-standardised. 
Figure 8:

Total fertility rate and desired family size by level of education, average of 30 countries

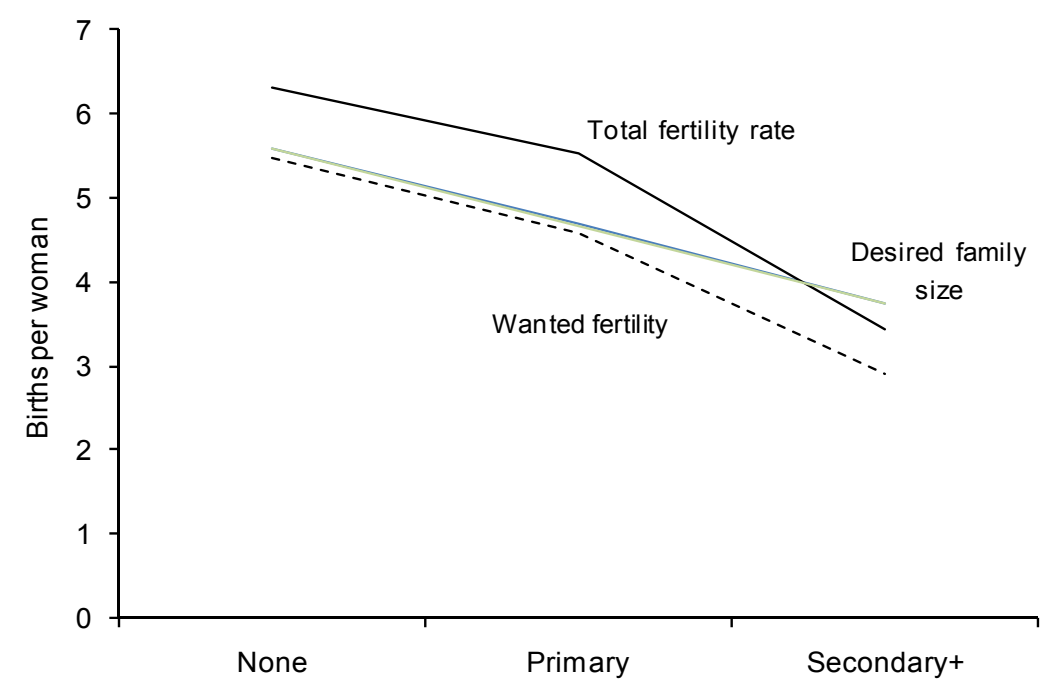

Source: DHS

Figure 9:

Demand for and use of contraception by level of education, average of 30 countries

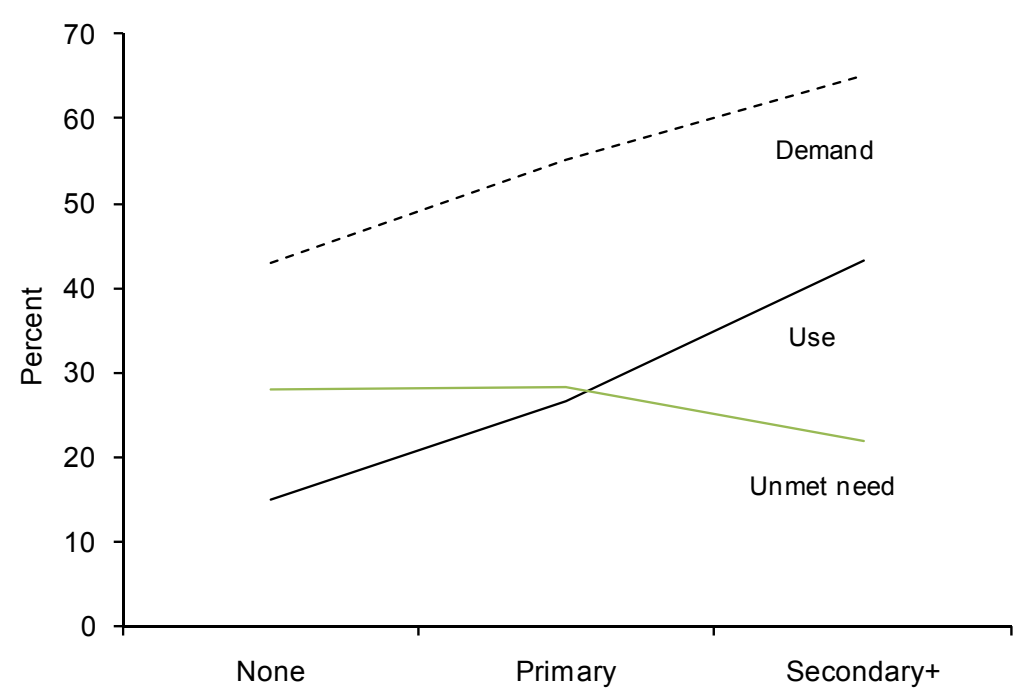

Source: DHS 
These relationships are as expected, but there is one surprising result in Figure 8: desired family size exceeds TFR among women with secondary or higher education (3.7 vs. 3.4 births per woman). This finding implies that a proportion of highly educated women do not reach their desired family size. This effect is even larger than suggested by the difference between desired family size and TFR because some births are unwanted. A comparison of the wanted TFR with desired family size indicates that the former falls short of the latter by a sizeable 0.82 births for women with secondary and higher education. In contrast, the wanted TFR is very close to the desired family size in groups with lower levels of education. Plausible reasons for this outcome are that highly educated women face greater obstacles in trying to implement their childbearing preferences. Such obstacles may be economic (high direct and opportunity costs of children), social (inability to find a suitable partner, late marriage, desire for a lifestyle or career incompatible with childbearing), or biological (risk of infertility at higher age).

\subsection{Country-level analysis}

The decline in desired family size and the rise in demand for and use of contraception with rising levels of education evident in Figures 8 and 9 are observed in each of the 30 countries. The negative association between the TFR and education level is almost as robust. The TFR among women with secondary and higher education is lower than for women with primary education in all 30 countries, and the TFR of women with primary education is lower than for women with no education in 27 countries. The exceptions are Chad, Congo (Brazzaville), and DR Congo, where fertility is highest among women with primary education. The explanation for these exception will not be pursued here but probably lies in the proximate determinants other than contraception (e.g. lower frequency of intercourse due to spousal separation among women with no education). In addition, women with no education are more likely to be undernourished, which could contribute to a higher risk of spontaneous abortion and stillbirth.

Next, the links between successive indicators are examined by level of education at the country level.

\subsubsection{Effect of contraceptive use on fertility}

Figure 10 plots the relationship between fertility and contraceptive prevalence, with each of the 30 sub-Saharan countries contributing three points, one for each level of education. The OLS regression lines fitted through these sets of points differ for two reasons. First, as the education level rises, the data points for each country (and the regression lines) shift to lower fertility and higher prevalence, as expected. Second, at a given level of contraceptive use, more education is 
associated with lower fertility. This result is most likely due to later marriage, more effective use of contraception and greater reliance on abortion among bettereducated women.

Figure 10:

Relationship between total fertility rate and contraceptive prevalence by level of education

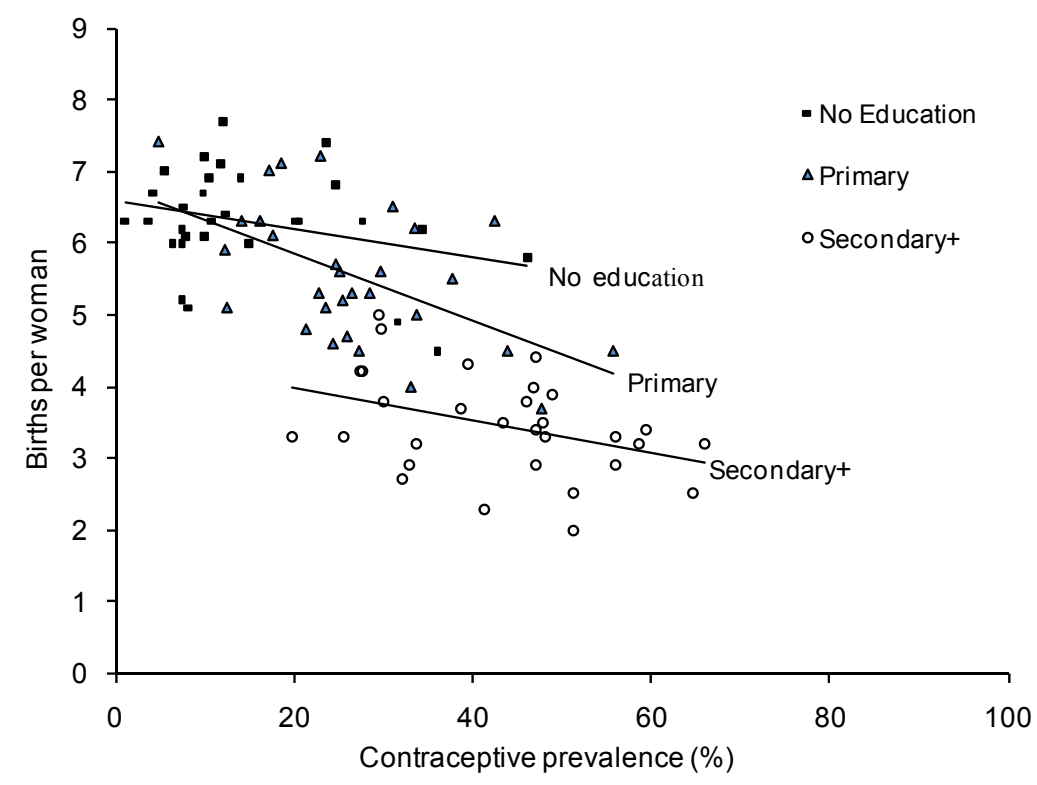

Source: DHS

\subsubsection{Effect of demand for contraception on contraceptive use}

Figure 11 plots the relationship between contraceptive prevalence and demand by level of education for 30 countries. With rising levels of education, the expected shift to higher levels of use and demand is evident. In addition, at a given level of demand, contraceptive use increases as the level of education rises. This finding is consistent with the conclusions from earlier studies that better-educated women have greater knowledge of contraception, higher autonomy to make decisions regarding their reproductive lives, better access to services, and greater motivation to implement demand (Jejeebhoy 1995; National Research Council 1999). 
Figure 11:

Relationship between contraceptive prevalence and demand by level of education

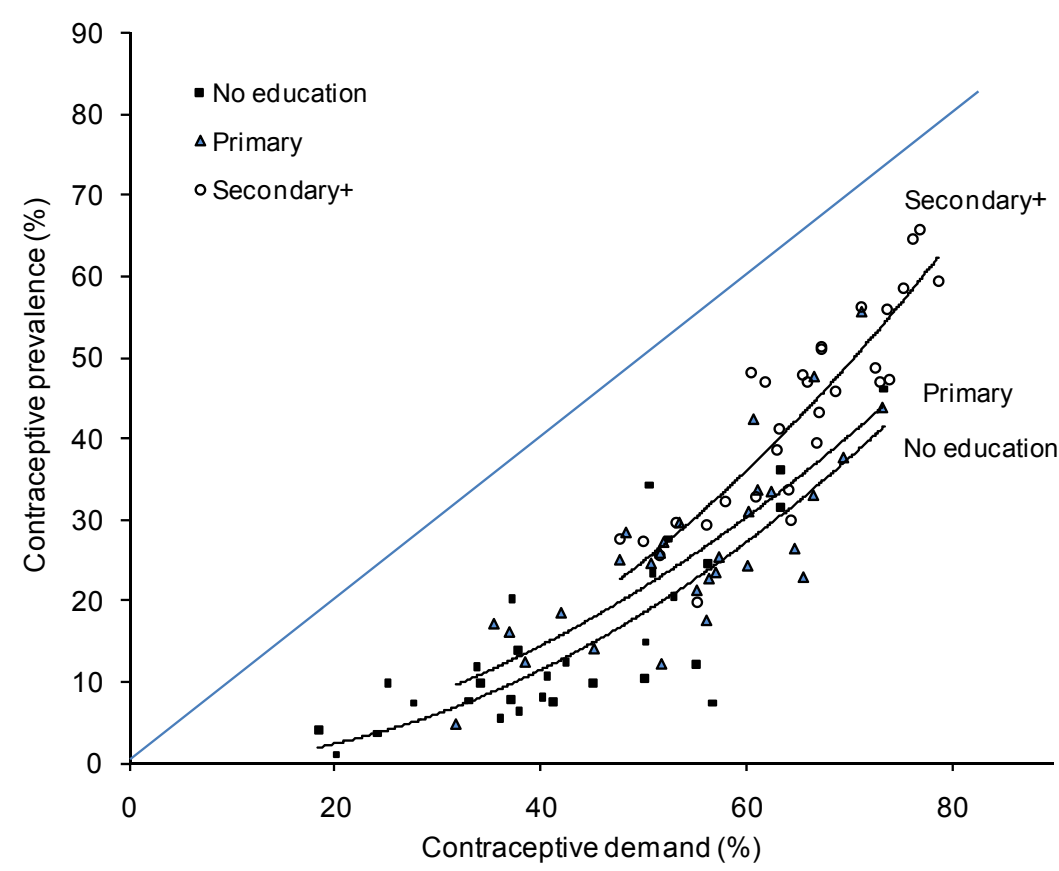

Source: DHS

\subsubsection{Effect of desired family size on the demand for contraception}

The expected inverse association between desired family size and demand for contraception exists for each education level (see Figure 12). The main finding of interest is that at a given level of desired family size, demand for contraception increases as the education level rises. A possible explanation for this result is that women with higher education have shorter periods of breastfeeding, thus requiring more contraception to maintain adequate birth spacing. Demand for limiting may also be higher because both the cost of unwanted births and obstacles to implementing preferences rise with level of education. 
Figure 12:

Relationship between demand for contraception and desired family size by level of education

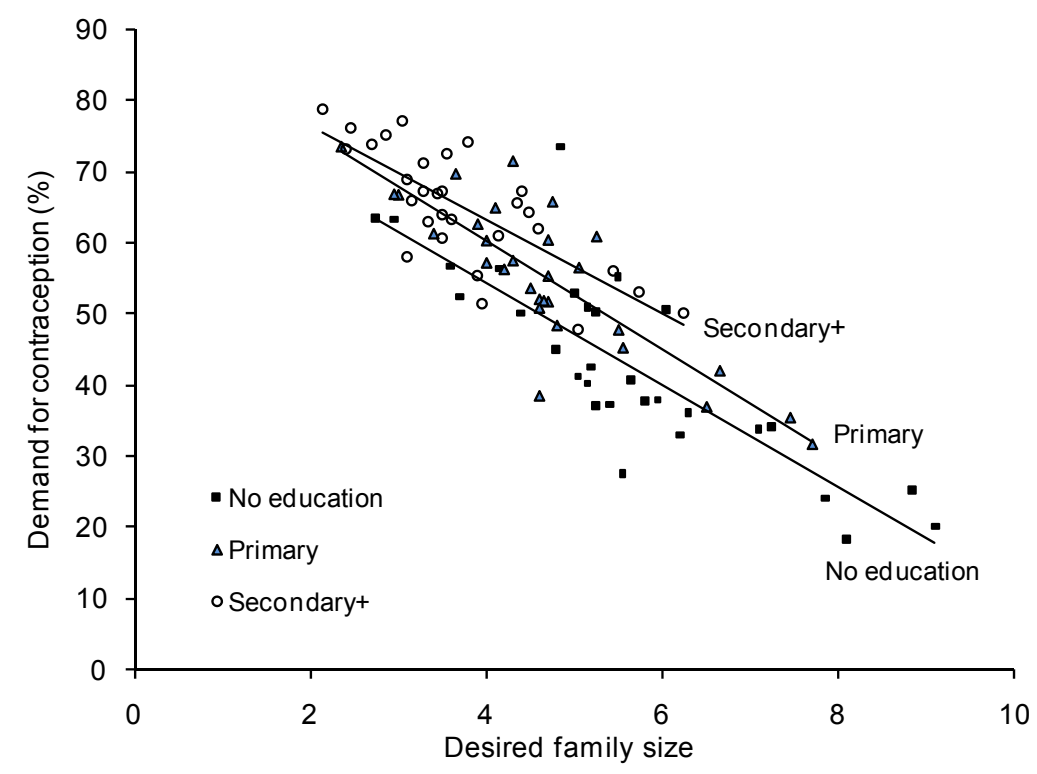

Source: DHS

\subsubsection{Unmet need for contraception and unwanted fertility}

As shown in Figure 13, the inverted U-shaped relationship between unmet need and demand for contraception is evident at each education level. At a given level of demand, higher education is associated with lower unmet need. The explanation is the same as for higher use at a given level of demand: more highly educated women have greater autonomy, more knowledge, better access to services and more motivation to avoid unintended pregnancy. The differences between education-specific proportions of demand satisfied presented in Figure 14 are explained by the same factors. 
Figure 13:

Relationship between unmet need and demand for contraception by level of education

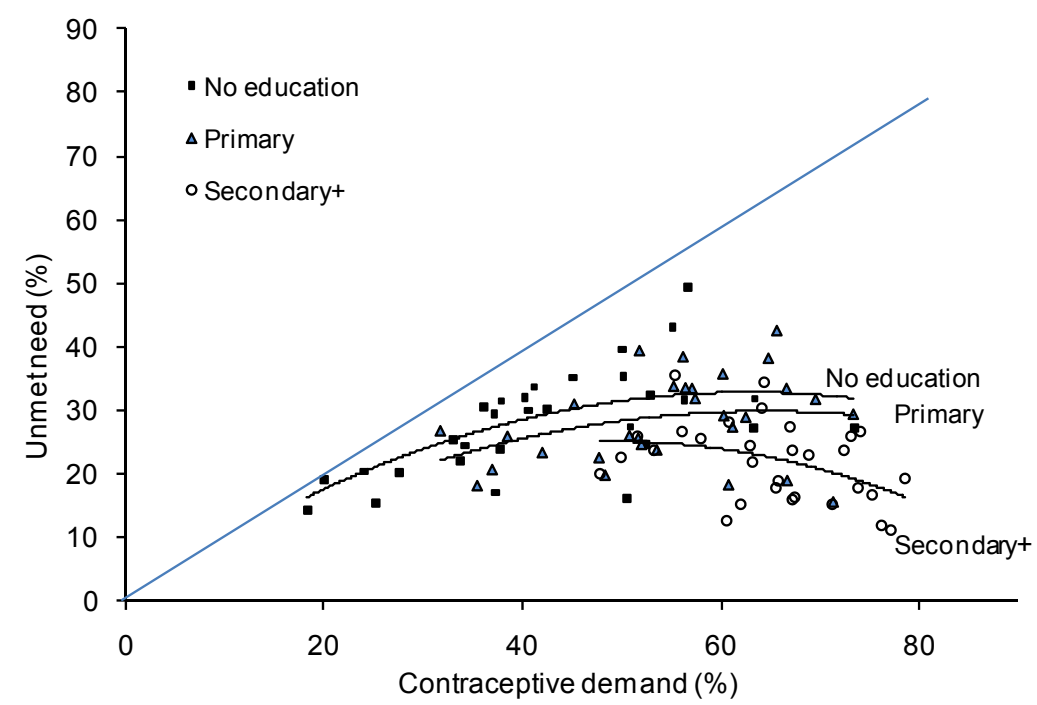

Source: DHS

Figure 14:

Relationship between percent satisfied and demand for contraception by level of education

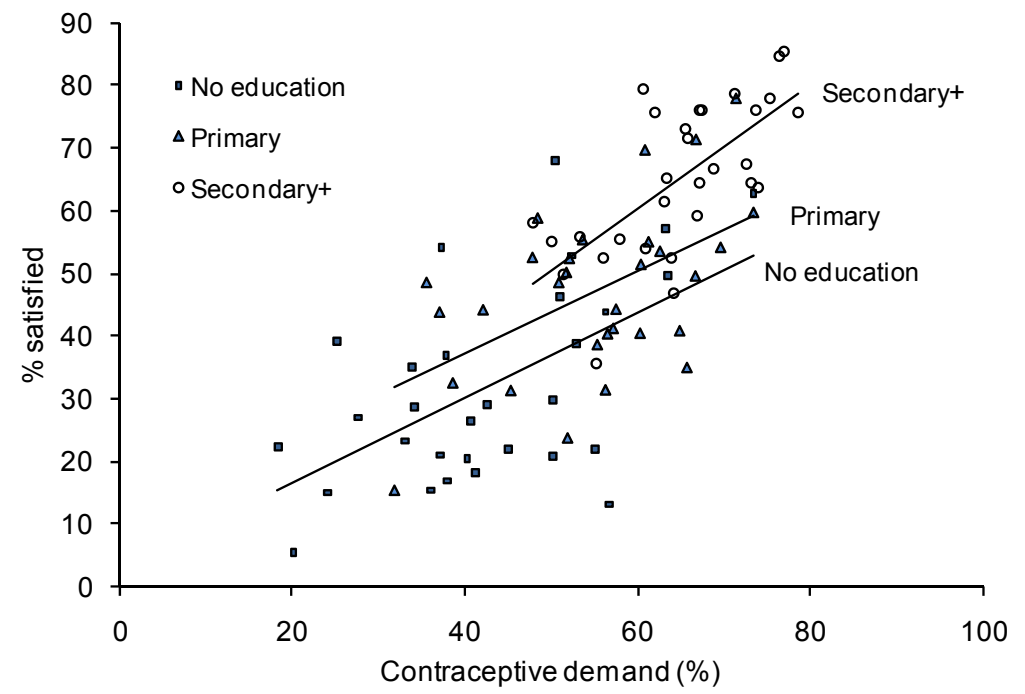

Source: DHS 
Finally, unwanted fertility exhibits a weak inverted U-shaped pattern for all three education levels (see Figure 15). As expected, unwanted fertility is lowest in the highest education group because women in this group have higher levels of satisfied demand and lower unmet need for contraception.

Figure 15:

Relationship between unwanted fertility and total fertility rate by level of education

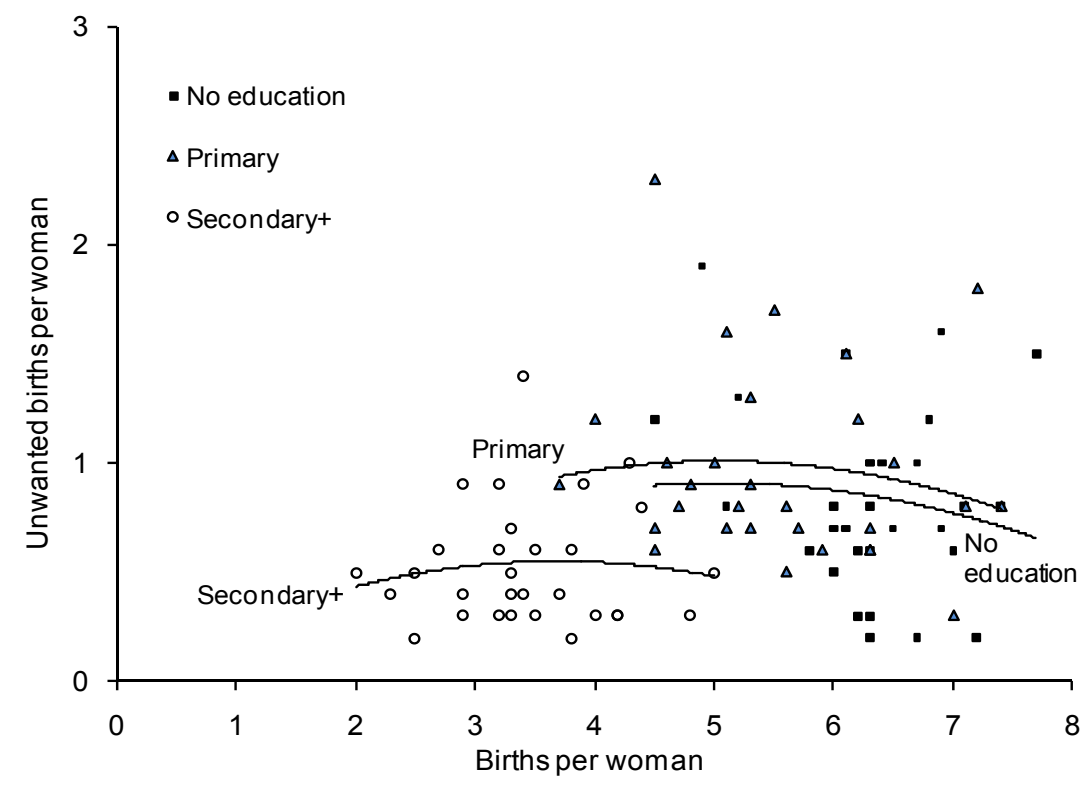

Source: DHS

\section{Conclusion}

Reproductive indicators differ widely among countries in sub-Saharan Africa, but the indicators have predictable associations. In countries with the highest fertility, demand for children is high and demand for and use of contraception is low. Conversely, in countries in which fertility has declined, desired family size is lower and both demand for contraception and women's implementation of this demand are relatively high. These findings are consistent with the conventional wisdom on the determinants of fertility.

Country-specific levels of unmet need for contraception and unwanted fertility show a less obvious inverted-U shape. Unmet need and unwanted fertility tend to rise in the early phases of the transition as a rising demand for contraception is left substantially unsatisfied; they peak in mid-transition and then decline in the later stages of the transition (despite still rising demand) as the proportion of this demand that is satisfied grows. 
Differences by level of education within countries are also generally consistent with the conventional wisdom: education levels are positively associated with demand for and use of contraception and negatively associated with fertility and desired family size.

In addition, there are differences by level of education in the relationships between indicators. As education rises, fertility is lower at a given level of contraceptive use, contraceptive use is higher at a given level of demand, and demand is higher at a given level of desired family size. The most plausible explanations for these shifting relationships are that better-educated women marry later and less often, use contraception more effectively, have more knowledge about and access to contraception, have greater autonomy in reproductive decision-making, and are more motivated to implement demand because of the higher opportunity costs of unintended childbearing.

\section{Acknowledgement}

The author gratefully acknowledges support for this research from the William and Flora Hewlett Foundation.

\section{References}

Bankole, A. and C. F. Westoff. 1995. "Childbearing attitudes and intentions." Demographic and Health Surveys, Comparative Studies No. 17. Calverton, MD, Macro International.

Bledsoe, C. H., J. B. Casterline, J. A. Johnson-Kuhn, and J. G. Haaga (eds.) 1999. Critical Perspectives on Schooling and Fertility in the Developing World. Washington DC, National Academy Press.

Bongaarts, J. 1997. "Trends in unwanted childbearing in the developing world." Studies in Family Planning 28(4): 267-277.

Bongaarts, J. and R. G. Potter. 1983. Fertility, Biology, and Behavior: An Analysis of the Proximate Determinants. New York, Academic Press.

Casterline, J. and S. W. Sinding. 2000. "Unmet need for family planning in developing countries and implications for population policy." Population and Development Review 26 (4): 691-723.

Caldwell, J. C. 1982. Theory of fertility decline. London, Academic Press.

Casterline, J. B. and S. Sinding. 2000. "Unmet need for family planning in developing countries and implications for population policy." Population and Development Review 26(4): 691-723.

Castro M. T. and F. Juárez. 1995. "The impact of women's education on fertility in Latin America: Searching for explanations.” International Family Planning Perspectives 21(2): 52-57.

Cleland, J. and G. Rodríguez. 1988. "The effect of parental education on marital fertility in developing countries." Population Studies 42(3): 419-442. 
Cochrane, S. H. 1979. Fertility and education: What do we really know? Baltimore, MD, Johns Hopkins University Press.

Jejeebhoy, S. J. 1995. Women's education, autonomy and reproductive behaviour: Experience from developing countries. Oxford, Clarendon Press.

Jeffery, R. and A. M. Basu (eds.) 1996. Girls' schooling, women's autonomy and fertility change in South Asia. New Delhi, Sage Publications.

Merrick, T. 2001. "Population and poverty: A review of reviews." In: N. Birdsall, A. C. Kelley, and S. W. Sinding (eds.), Population Matters: Demographic Change, Economic Growth, and Poverty in the Developing World. New York, Oxford University Press, pp. 201-212.

Rodríguez, G. and R. Aravena. 1991. "Socioeconomic factors and the transition to low fertility in less developed countries. A comparative analysis." Paper presented at the Demographic and Health Surveys World Conference, Washington DC, August 5-7.

Ross, J., J. Stover, and D. Adelaja. 2005. Profiles for family planning and reproductive health programs: 116 countries. Second edition. Glastonbury, Connecticut, The Futures Group.

Rutstein, S. 2002. "Fertility levels, trends and differentials: 1995-1999." Demographic and Health Survey Comparative Reports No. 3. Calverton, MD, Macro International, Inc.

Singh, S. and J. Casterline. 1985. "Socioeconomic determinants." In J. Cleland and J. Hobcraft (eds.) Reproductive Change in Developing Countries. Oxford, Oxford University Press, pp 199-222

United Nations. 2001. Levels and trends of contraceptive use as assessed in 1998. Department of Economic and Social Affairs, New York, United Nations.

United Nations. 1987. "Fertility behavior in the context of development: Evidence from the World Fertility Surveys." Population Studies, no. 100. New York, United Nations.

United Nations. 1995. Women's Education and Fertility Behavior: Recent Evidence from the Demographic and Health Surveys. New York, United Nations.

United Nations. 2007. World Population Prospects: The 2006 Revision. New York, United Nations. 